\title{
Astronomy Research Seminar Expansion and Building a Community-of-Practice
}

\author{
Rachel Freed ${ }^{1 *}$
}

\begin{abstract} around student astronomical research.

\section{Keywords}

Community of Practice - student research - astronomy education

${ }^{1}$ Institute for Student Astronomical Research, California, USA

*Corresponding author: r.freed2010@gmail.com
\end{abstract}

The astronomy research seminar has been growing by leaps and bounds over the past several years and is now offered in almost a dozen institutions from middle schools up through community college and undergraduate courses in four-year universities. In its spread it has gone through diversification in how it is taught to fit the needs of the new instructors, students and institutions, whether it's as a three-day intensive workshop, eight-week fully online seminar or semester-long hybrid course. An important part of the growth, success and sustainability of an astronomy research seminar is having student teams working within a Communityof-Practice. Key to this, is building up that Community-of-Practice and helping students understand that they are important partners within the community. This paper presents brief descriptions of many of the seminar offshoot programs in the context of building a Community

\section{Introduction}

For several decades it has been recognized that science education and career-readiness in the US are on the decline (National Research Council 2011; Kastberg et al. 2016) and many governmental and educational organizations have tried to determine how to reverse this trend, from improving teacher education programs (National Research Council 2010), increasing STEM motivation in students (Johnson 2012), and completely rewriting national science standards (NGSS Lead States 2013), among other things. Many studies have pointed out that astronomy is the "Gateway Science" (National Research Council 2011), and the author can attest to the intrinsic draw astronomy has on the public imagination and interest based on more than 20 years of public outreach in astronomy. Translating the way that astronomy can capture the attention of people of all ages into a way for them to learn about the nature of science and scientific inquiry may well help direct students into STEM education and career pathways. Keeping the fascination of the subject alive within the educational context is crucial for maximal impact and the Astronomy Research Seminar (ARS), pioneered and taught by Russell Genet for over 10 years (Freed et al. 2017; Freed 2018), may well serve this role.

Astronomy education comes in a tremendous variety of forms, from the large-scale Astro101 college courses, some implementing telescope access remotely and some not, to other large universities and small community colleges with their own telescopes for hands-on use, to MOOCS with or without student access to telescopes, to high school astronomy courses and after-school programs, as 
well as the myriad of informal astronomy education programs around the globe. Many programs over the years have attempted to implement telescopes into education, as outlined by Gomez and Fitzgerald (2017), with varying amounts of success and longevity. Evaluation of many of these programs has been ongoing for years or may just be beginning and each serves an important role for its population. This evaluation is critical to understanding the true impact of these programs and to help improve them.

The Astronomy Research Seminar appears to be providing critical learning and motivation for those students it serves in its variety of settings and incarnations which will be expanded upon below. It certainly serves a different community of learners from those in a large university or MOOC setting, with the Seminar's emphasis on students working directly with advanced amateur astronomers or experts in their particular field of research. The strong focus on student-led diverse teams and writing for publication, guided by members within the larger Community-of-Practice, also distinguishes this program from most others, and seems to provide an entryway into STEM as a hobby or education or career path for some students who might not otherwise have clear access to these.

It is thought that the ongoing development of a Community-of-Practice around student astronomical research is one of the contributing factors to the success of the program over the past decade, with success being defined as numerous students undergoing at least a small identity change in seeing themselves as scientists or as contributing meaningfully to science. Wenger (1999) states in his seminal work, Communities of Practice: Learning, Meaning, and Identity, that learning "transforms our ability to participate in the world by changing all at once who we are, our practices and our communities" and "Education design must engage learning communities in activities that have consequences beyond their boundaries, so that students may learn what it takes to become effective in the world." It is the case that many students, having gone through the seminar once, then go on to do it again and bring others into the program or build their own programs.

\section{Expansion of the Astronomy Research Seminar}

The Astronomy Research Seminar (ARS) has expanded significantly over the past three years. After initially being offered through Cuesta Community College in San Luis Obispo, CA, it is now offered by numerous institutions and organizations throughout the country, either in-person or as a hybrid or totally online course. In its spread it has taken on several different forms over the years as discussed below. As Wenger et al. (2002) points out, one of the seven principles for cultivating communities of practice is to design for evolution: "As the community grows, new members bring new interests and may pull the focus of the community in different directions...Community design is much more like life-long learning than traditional organization design".

As many of the organizations that have embraced the Astronomy Research Seminar have shown, the interests of its members have lead them to develop and promulgate new versions of the seminar with diverse audiences with a far-reaching domino effect helping to keep the Community-of-Practice dynamic and alive. It is important to note that the goal of expansion of the seminar is NOT to make a handful of identical programs at different institutions, but rather to share lessons learned about how to have students do research and publish their results, to share resources created for these purposes, and to provide assistance as needed for new programs to establish themselves in the manner that best suits their local communities.

Figure 1 attempts to show some of the connections between organizations, individuals and schools through which the Astronomy Research Seminar and student astronomical research has recently propagated. It is by no means an exhaustive portrayal of people and institutions involved. The individuals, shown in purple, have helped student teams and instructors at various institutions. A few of the high schools (in blue ovals) and community colleges (in green ovals) which have taken on or created their own version of the Astronomy Research Seminar in the past few years are shown, as 
are conferences and organizations (in orange) that have supported student research, publication and presentations. This represents a small snapshot in time, between 2016-2018, and could include more community members on the periphery and interwoven amidst the schools and organizations. It would be difficult to capture the full interconnectedness of the community and its expansion, as it is alive, dynamic and growing.

To illustrate the growth and expansion of the seminar, a variety of different implementations at different institutions are outlined below beginning with the original "Astronomy Research Seminar".

\section{Cuesta Community College}

The Astronomy Research Seminar originated at Cuesta Community College in San Luis Obispo County, CA. It has been taught there almost continuously since 2008, for the first six years as an in-person course and then with fully online and hybrid versions also available since 2014 . The course has often had both undergraduate students and high school students from the local area. Student teams consisted of mixed levels of students with varying skill sets. Whether meeting in-person or online, teams met with their instructor once a week and were required to meet on their own at least once a week in addition, as a major seminar goal is for students to learn to take responsibility and ownership of their research. The students were sometimes recruited from advanced math courses and sometimes from the general school population and had students from a diverse range of majors.

\section{Other Institutions providing the in-person ARS}

The Seminar was occasionally taught in the winter as an in-person course at Maui Community College, in Kahului, Hawaii. Between 2010-2012 there were also versions of the seminar at Evergreen State College in Olympia, WA, revolving around a weekend at Pine Mountain Observatory in Deschutes National Forest, near Bend, Oregon. Students would come to the observatory, learn how to use the telescopes, collect their data and then return home to finish writing up their papers. This program contin- ued in the summer of 2018 .

\section{Offshoots of the Astronomy Research Seminar}

\section{Apple Valley Double Star Workshop (AVDSW)}

Mark Brewer took the seminar as a junior in college in 2011, resulting in the first of his 13 publications (Brewer et al. 2012), and loved it so much he immediately started his own version which he provided for students from middle school up to college as well as the general public. He advertised to the local school district and did fundraising at various places such as Walmart and Starbucks, advocating for the research seminar and how it benefited the public. He ran the workshop with assistance from others from 2012-2016, and the tradition was carried on after 2016 by the High Desert Research Initiative (Brewer et al. 2016). Approximately 70 participants participated in the workshops over the five years and most of Brewer's 13 publications include numerous students. He has written about and presented his double star research program at the Society for Astronomical Sciences Annual Symposium (Brewer et al. 2014).

\section{Vanguard Double Star Workshop (VDSW)}

Sean Gillette first participated in the Astronomy Research seminar under the guidance of Mark Brewer, a former seminar student, at the Luz Observatory at the Lewis Center for Educational Research in Apple Valley, CA in 2011, co-authoring a paper on visual measurements of several binary star systems (Brewer et al. 2012). He then started the Vanguard Double Star Workshop (VDSW) research program at Vanguard Preparatory Academy where he taught science until mid-2018. Approximately 30 eighth grade students have participated each year, beginning in 2014, with 36 in the program in the Fall of 2018, and culminating in a total of nine published student papers and several more in preparation (Gillette et al. 2017). This program is significantly different than the eight-week or semesterlong course taught at most institutions. The students participate in a three-day intensive workshop in which they take measurements at the telescope, 


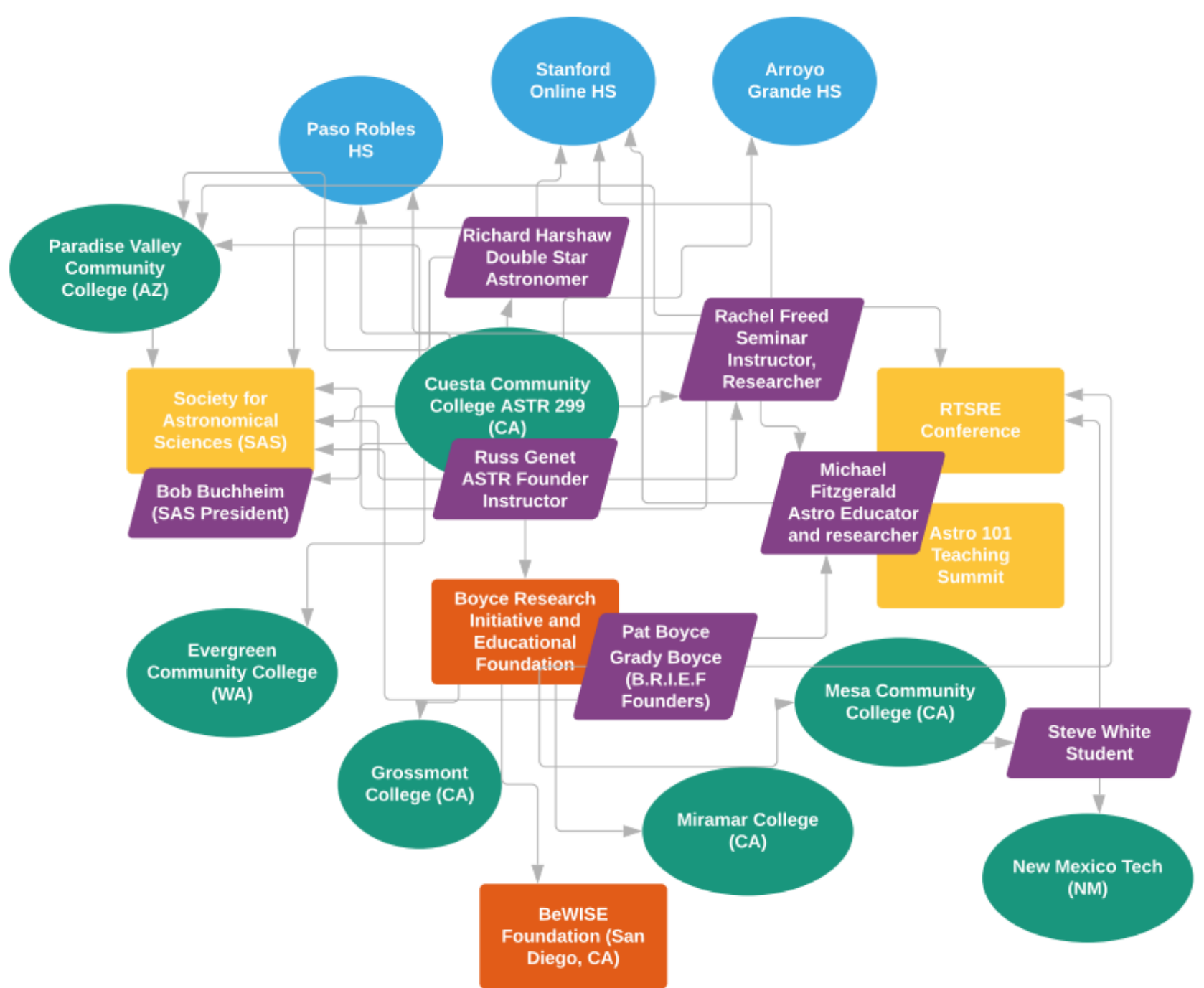

Figure 1. The Expanding Community-of-Practice around the Astronomy Research Seminar - a snapshot in time. Light blue ovals are high schools that provide the Astronomy Research Seminar. Green ovals are community colleges that provide a research seminar. Purple parallelograms are individuals who play a role in disseminating or supporting student astronomical research. Yellow boxes are conferences that support student astronomical research.

analyze the data and write up their results.

\section{Evergreen State College, Olympia, WA}

In 2010 and 2011 Rebecca Chamberlain, an instructor at Evergreen State College, worked with Russ Genet to provide the Astronomy Research Seminar to community college students. They went to the Pine Mountain Observatory Summer workshops to collect data and published six papers in 2011 and 2012. Recently, Evergreen State College partnered with the Institute for Student Astronomical Research (InStAR) in the Summer of 2018 to again provide the seminar for ten community college students as well as a high school student from Irvine, CA. This new version had student teams meeting with the Evergreen instructor in person once a week while the InStAR seminar instructor joined the class remotely via Zoom. In addition, the InStAR instructor met with the students via Zoom as needed to answer questions and help solve problems. The student teams also met independently throughout the eight-week seminar and have two papers in preparation for submission for publication 
(e.g. Pangalos-Scott et al. (2019)). The partnership is continuing in the Fall of 2018 and the Summer course will be offered again in partnership in the summer of 2019.

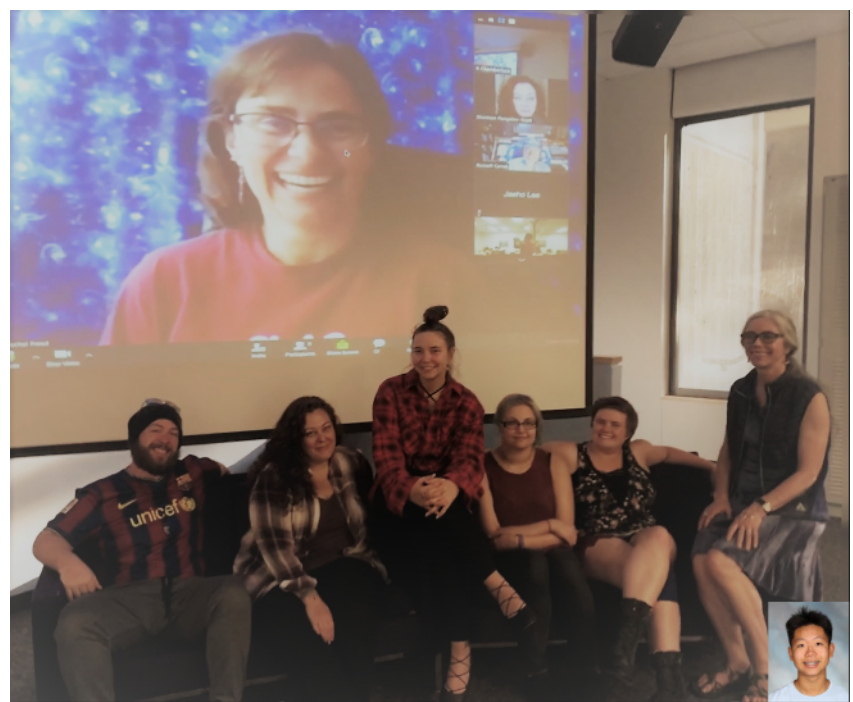

Figure 2. Group Photo, left to right. Zach Medici, Shannon Pangalos-Scott, Danielle Holden, Micaiah Doughty, Melody Fyre, Rebecca Chamberlain, at The Evergreen State College, Olympia, WA.

Rachel Freed, in the background; Jaeho Lee, in the bottom right.

Research, which has been verified in recent interviews with students (Freed 2019), shows that having actual time at the telescopes critically enhances the learning experience in terms of student understanding of how data is collected. In addition, students feel more connected to the research and have a sense of ownership of their work. Recently, Evergreen State College in Olympia, Washington, had seminar students who attended Pine Mountain observatory and were actually able to observe their double stars on a 0.7-meter telescope. They had already collected and analyzed data using the LCO 0.4-meter telescopes and they expressed an incredible sense of connection and pride in seeing these stars they had been studying.

Currently, in the Fall of 2018, four students who took the Evergreen/InStAR seminar have embarked on a new round of research projects on double stars and recruited new students to join them. This has spurred the development of a follow-on seminar by the InStAR team, which has been proposed many times over the past decade. In this course, students will take on mentorship roles in addition to the research roles they had in their first seminar experience. They have a goal of disseminating the seminar to local high school students in 2019 and serving as instructors at that point. Furthermore, they will be presenting their research at the Conference for Undergraduate Women in Physics, helping them build upon and strengthen their own Communities of Practice.

\section{BOYCE-ASTRO and the San Diego Area}

In the San Diego CA area the Boyce Research Initiatives and Education Foundation (B.R.I.E.F) has established the BOYCE-ASTRO program which works with three community colleges in the area, Mesa College, Grossmont College and San Diego Miramar College, as well as BE WISE (Better Education for Women in Science and Engineering) and several other organizations to provide astronomy research opportunities to high school and undergraduate students. They have served over 200 students and have produced 33 student publications since the Spring of 2015. Links to these publications can be found on their website at http://boyceastro.org/library/.

While the BOYCE-ASTRO program initially modelled their courses after the Astronomy Research Seminar taught by Genet, they have expanded significantly, creating their own model for teaching astronomy and having students conduct and publish research, building an impressive collection of educational materials for this purpose. They have incorporated many of the educational technology tools that students are already naturally inclined to use, such as Remind (https://www.remind.com) and Ed Puzzle (https://edpuzzle.com/) to create dynamic and interactive learning materials (Boyce and Boyce 2017). The BOYCE-ASTRO program is now working with TESS (Transiting Exoplanet Survey Satellite; https://tess.gsfc.nasa.gov/) followup programs to have students observe candidate exoplanets in collaboration with NASA. 


\section{Stanford University Online High School (OHS)}

Stanford University Online High School (OHS), is a fully online, accredited high school run out of Stanford University in Palo Alto, CA. Students in the program live at various locations around the world. Kalee Tock, a science instructor at OHS, and one of her 8th grade students participated in the seminar in the Fall of 2016. Tock then provided the seminar as an extracurricular program for one year and has now developed a course at OHS for astronomy research (Tock 2018). By connecting with the larger Community-of-Practice, in particular with significant guidance from Michael Fitzgerald of Our Solar Siblings (Fitzgerald et al. 2018), Tock has provided the opportunities for her students to study eclipsing binaries (EBs), RR Lyrae stars and exoplanet transits in addition to developing computer models to study orbital parameters.

The students also write python code for analyzing large quantities of EB data. (See Badami et al. 2018; Hensley 2018; Hensley et al. 2018; Kith et al. 2018). Several papers are still in preparation and a new cohort of approximately 20 students has begun the seminar this Fall. Several students from OHS presented their research at the second annual conference on Robotic Telescopes, Student Research and Education (RTSRE) in Hilo, Hawaii, in June of 2018, and another presented his research at the InStAR workshop held in June 2018, in Ontario, California (Figure 3). Additionally, Tock now gives workshops on how to provide the Astronomy Research Seminar and how to use Google Collaboratory, for students to work together on these sorts of research projects. Her students are already being scheduled to present their research in New York and Southern California in 2019.

Paradise Valley Community College, Arizona In Arizona, the Astronomy Research Seminar is provided at Paradise Valley Community College which had its first student teams in the Spring of 2018. Six students, five girls and one boy, from Paradise Valley and Foothill Academy High School, worked with their team members and used a C-11 with an attached ZWO ASI290MM camera at Brilliant Sky Observatory, owned and operated by Richard

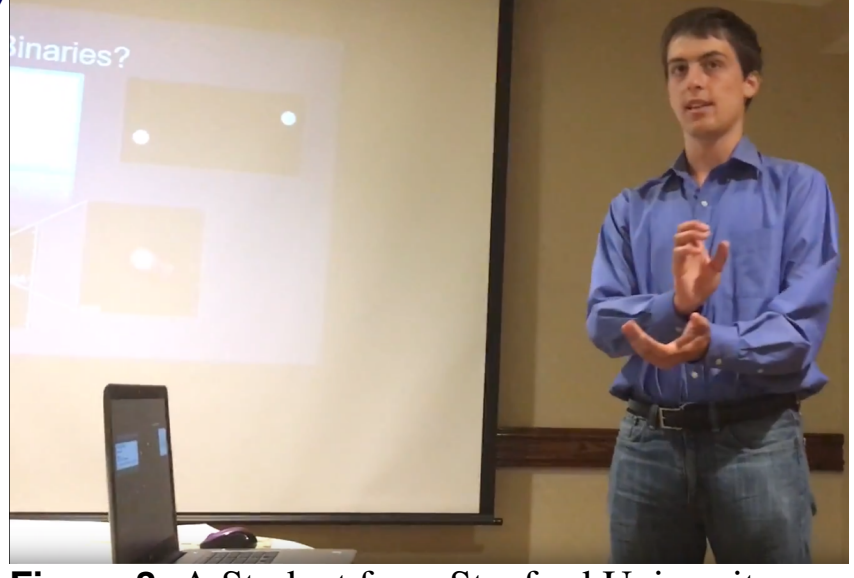

Figure 3. A Student from Stanford University Online High School presents his team's research at the InStAR workshop in Ontario, CA in June 2018.

Harshaw, to study the double star STF 1427. Harshaw has been studying and publishing double star research for several decades, having published measurements of over 1000 double star pairs (Harshaw 2018; Harshaw and Cave Creek 2017), and over the past five years has helped numerous student teams throughout California and Arizona conduct research. Three of the team members presented their work at an InStAR workshop held in Ontario, CA in June 2018 (Figure 4). The audience of other college professors, astronomy curriculum and lab developers, observatory operators, and advanced amateur astronomers who conduct and publish research provided an authentic audience for these students for whom research and presenting their work was all quite new. Their paper is in preparation for submission to the JDSO.

\section{Paso Robles HS, Paso Robles, CA}

In the Spring of 2018 Jon-Paul Ewing, a physics instructor at Paso Robles HS, joined an Astronomy Research Team at Cuesta College to learn how to provide research experiences for his high school students. After submitting a paper for publication in the JDSO (Andersen et al. 2018) Ewing lead a team of nine girls (Figure 5) through the research seminar in the Summer of 2018. Their paper was accepted on September 3rd, 2018, for publication in the Journal of Double Star Observations (JDSO). 


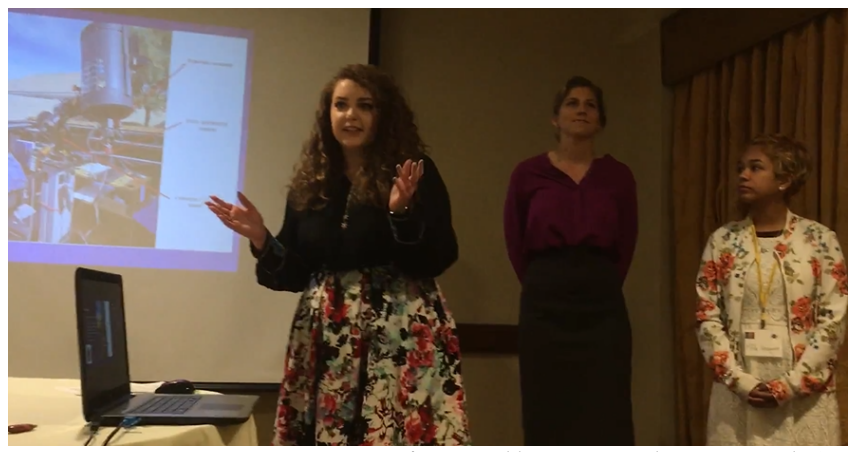

Figure 4. Two community college students and 1 high school student from Arizona present their research at the InStAR workshop in Ontario, CA in June 2018.

Included in their seminar was a trip to Mount Wilson where they had time on the 2.5-meter telescope, although their data collection for the research was actually done on one of the Las Cumbres Observatory 0.4-meter telescopes. (Phillips et al. 2019)

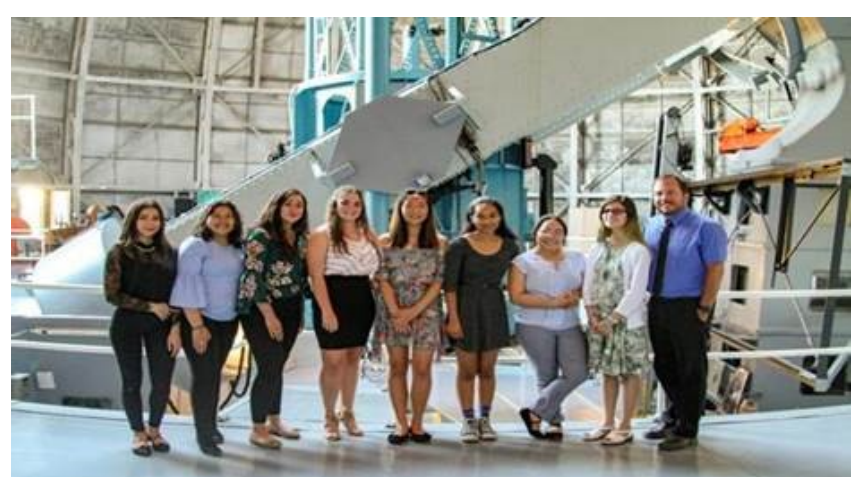

Figure 5. Students from Paso Robles High School and their Instructor, Jon-Paul Ewing, at Mount Wilson Observatory, Summer 2018

\section{College of the Desert, Palm Desert, CA}

This is a public two-year college, dedicated as a Hispanic Serving Institution, in the ethnically diverse Coachella Valley. It has recently acquired a 1-meter PlaneWave Instruments telescope and is adapting the Astronomy Research Seminar for students enrolled in its Research Experience for Undergraduates program (ElShafie et al. 2018). Their observatory operator has attended several InStAR Workshops over the past year, most recently in June 2018, in preparation for coordinating student research and publication programs at the school.

\section{Mt. San Antonio College (Mt. SAC), Walnut, CA}

Over the past year three astronomy instructors from Mt. SAC have attended several different InStAR workshops and one recently sat in on a two hour Zoom meeting with an instructor and students as they worked on refining their research paper for publication. One of the key lessons learned over time is that educators are best able to conduct the Astronomy Research Seminar once they have gone through the Seminar themselves. To that end, immersing new instructors in the course is invaluable to their success and these new seminar instructors will be supported in their development of a research program.

\section{InStAR Courses}

The first InStAR Course was taught as a hybrid course in collaboration with Evergreen State College in Olympia, WA. Starting in October of 2018, several new InStAR online courses will be provided, one for studying exoplanets, and one for double star astrometry in conjunction with GAIA DR2 analysis. These can be found at https://www.in4star.org/. Over the past half-decade InStAR has created numerous resources for student research with small telescopes and publications. These include videos about the processes of conducting research, writing papers, and many tutorials about how to use software programs to do data analysis. Additionally, it has produced an online Canvas course and the Small Telescope and Astronomical Research Handbook (Genet et al. 2015) which serves as a text for the courses and a guide to those generally interested in small telescope astronomical research.

\section{Seminar Material Development}

Over the past three years many resources have been developed in addition to the InStAR handbook. These include mini tutorial videos on YouTube and they are constantly being added to as new questions arise. For example, in response to student questions, videos have recently been developed to explain how to use AstroImageJ and astrometry.net and how to add new data points to the orbital diagram using measuring tools within PowerPoint. Additionally, a 
full course has been developed in the Canvas Learning Management System which is available to new instructors and students. The program continues to grow and develop organically in a fashion similar to the way science itself is conducted, with new questions and obstacles leading to new research and experimentation.

\section{Future Directions}

The Astronomy Research Seminar's success in influencing student pathways in STEM and helping change their identities as scientists is put in the framework of working within a Community-of-Practice and a requisite goal for sustainability and growth of the program is expanding that Community-of Practice. To that end numerous workshops have been held and more are being scheduled next year. One of the most important meetings/movements to come out of trying to broaden and build a larger Community-of-Practice was the first annual Conference on Robotic Telescopes, Student Research, and Education (RTSRE) that took place in June, 2017. That conference, organized mainly by Michael Fitzgerald from Edith Cowan University, Pat Boyce from San Diego, California, and Russ Genet from Cal Poly San Luis Obispo and Cuesta College, brought together many players in the greater arena of telescopes in education, astronomy curriculum development and evaluation, remote observatory owners and designers and both formal and informal astronomy educators. Likely the most impactful result of that first RTSRE conference was the Call for Proposals from the Las Cumbres Observatory (LCO) Education Partnership (Gomez 2018) which led to about 18 institutions having access to the network of 0.4-meter LCO telescopes for use with students and in informal education environments. That education partnership has expanded with a new call for proposals for partnerships for 2019 and a selection of 21 total partners. According to the LCO Global Director at that time, Todd Boroson, LCO had been trying for a long time to reach out to a large segment of the educational world, and it was really the conversations at the first RTSRE conference in 2017 that led to the expansion of the Education Part- ners program. The 2 nd annual RTSRE conference was held in Hilo, Hawaii in July 2018 and out of that came a Skynet call for collaborators. Skynet (Reichart et al. 2005) is one of the largest global and networked collection of telescopes, along with LCO, and this, combined with the LCO Education partnerships, marks the beginning of a cohesive, global effort to provide telescope access to as many students in as many countries as possible, providing the necessary framework on which to continue to expand the astronomy research seminar. Of course, the community needs not only the telescopes, but the people as well and to this end monthly online emeetings have been developed to help build and support this growing Community-of-Practice around student research. While the Skynet call for collaborators is focused more on the study of its Astro101 and higher level curriculum impacts, there are numerous Research Seminar Instructors who are part of the Skynet group and therefore, their student teams have access to these telescopes for research projects. Another avenue to expand the research seminar approach is in providing a continuing education course for pre-service and in-service teachers based on the astronomy research seminar, allowing for more educators in the $\mathrm{K}-12$ arena to bring authentic research experiences to their students in collaboration with language arts and education specialists. This program is under development at Sonoma State University in the School of Education with a goal of providing the course in the Summer of 2019. The Astronomy Research Seminar has begun to expand from the initial domain of double star astrometry to other astronomical arenas available to small telescopes (0.4 - 2-meters), such as Exoplanet transits, asteroid photometry and eclipsing binaries. In addition, a collaboration with several radio astronomy organizations, including GAVRT, (Gladstone Apple Valley Radio Telescope) and Skynet with their 34" meter radio dish at Greenbank Observatory in West Virginia, is in development to incorporate the use of radio telescopes and projects for which they are especially capable of such as the study of intraday variable blazars, solar phenomena recorded over month-long time scales, synchrotron radiation effects on the Juno mission, 
and other radio observations. It is interesting to note how members within a large Community-ofPractice may flow from one arena to another over time, bringing their experience and expertise to a new domain. Sean Gillette, who ran the Vanguard Academy Double Star Workshop for 8th graders, now works for the GAVRT team at the Lewis Center for Educational Research and can bring his years of experience with the Astronomy Research Seminar to bear on this new collaboration. Finally, in an effort to expand awareness of and participation in the astronomy research seminar, several workshops are being scheduled around the country for 2019, so far in Houston, TX, Suffern, NY, Fort Davis, TX, Provo, UT and Ontario, California, with others potentially being conducted. The goal of these workshops is to bring together local astronomy educators, students, and amateur and professional astronomers, and to give them training on how to conduct a successful research seminar with a student publication at the end, and to connect them all to the larger Community-of-Practice in order to ensure sustainability.

\section{Conclusion}

Over the past several years the Astronomy Research Seminar has taken on a life of its own, spreading throughout the country and globally through its various in-person and on-line personas. It has clearly moved on past the "founder effect" and hundreds of students are gaining the experience of participating in true scientific research, publishing their results and working within a Community-of-Practice larger than their school districts and college campuses. Many of the offshoots of the original seminars provided at Cuesta College are still running, even four years after their founding, and new programs are being developed each year. Access to at least two large, global telescope networks, with web-based interfaces, removes one of the biggest obstacles for astronomical research for students, and the expanding community will hopefully provide enough support for it to achieve long-term sustainability. Furthermore, branching out from double star research, into other areas of astronomy that students and the public are excited about, such as exoplanets and asteroids, as well as diversifying to include radio astronomy, will likely help propagate and sustain the research seminar further. Student-led astronomical research, publication and communication, aligns very well with the Next Generation Science Standards as well as Common Core standards, and is therefore perfectly situated to be adopted within high school science courses. Providing workshops for educators and the amateur astronomy community with the expertise to support them will hopefully allow these programs to flourish, and students to become more scientifically literate, as they become the voters and policymakers in the not-toodistant future.

\section{References}

Andersen, B., Ewing, J.-P., Griffin, A., Lopez, B., Reupold, K., Pham, K., Freed, R., Harshaw, R., and Genet, R. (2018). Astrometry of STF 1985 Shows Continued Off-Orbit Path. Journal of Double Star Observations, 14.

Badami, U. A., Tock, K., Carpenter, S., Kruger, K., Freed, R., and Genet, R. M. (2018). Measurement of the Position Angle and Separation of HJ 1924. Measurement, 14(1).

Boyce, P. and Boyce, G. (2017). A CommunityCentered Astronomy Research Program. In Society for Astronomical Sciences Annual Symposium, volume 36, pages 107-122.

Brewer, M., Estrada, C., Estrada, R., and Gillette, S. (2016). A Weekend Workshop on Double Stars for Students. Journal of Double Star Observations, page 9 .

Brewer, M., Rogers, A., Harder, H., Lazak, R., Gillette, T., Gillette, S., Sweatt, M., Keele, R., Keele, M., Smith, B., et al. (2012). Student Measurements of 3 Binary Star Systems. Journal of Double Star Observations.

Brewer, M., Weise, E., Estrada, R., Estrada, C., Buehlman, W., Wasson, R., Rogers, A., and Camunas, M. (2014). Apple Valley Double Star 
Workshop. Journal of Double Star Observations, 10(2).

ElShafie, A., Garcia, R., Jacobsen, J. M., Murguia, G., and Ocegueda, A. (2018). Mary Reagan 1Meter Telescope Observatory at College of the Desert. In Society for Astronomical Sciences Annual Symposium, volume 37, pages 145-147.

Fitzgerald, M. T., McKinnon, D. H., Danaia, L., Cutts, R., Salimpour, S., and Sacchi, M. (2018). Our Solar Siblings. A high school focussed robotic telescope-based astronomy education project. RTSRE, 1(1):221-235.

Freed, R. (2018). Astronomy Research Seminar: The Impact on Students from their Perspective. Preliminary results from one spring seminar. $R T$ SRE Proceedings, 1(1).

Freed, R. (2019). Evaluation of the Astronomy Research Seminar. RTSRE Proceedings, 2(1).

Freed, R., Fitzgerald, M., Genet, R., and Davidson, B. (2017). An overview of ten years of student research and JDSO publications. In Society for Astronomical Sciences Annual Symposium, volume 36, pages 131-136.

Genet, R., Johnson, J., Buchheim, R., and Harshaw, R. (2015). Small Telescope Astronomical Research Handbook. Ed. Collins, D.

Gillette, S., Wolf, D., and Harrison, J. (2017). Engaging Teenagers in Astronomy Using the Lens of Next Generation Science Standards and Common Core State Standards. SASS, 36:123-130.

Gomez, E. (2018). Las Cumbres Observatory: Networking people and telescopes for science and education. RTSRE, 1(1):243-244.

Gomez, E. L. and Fitzgerald, M. T. (2017). Robotic telescopes in education. Astronomical Review, 13(1):28-68.

Harshaw, R. (2018). Measurements of 427 Double Stars With Speckle Interferometry: The Winter/Spring 2017 Observing Program at Brilliant Sky Observatory, Part. Measurements, 14(2).
Harshaw, R. and Cave Creek, A. (2017). The Spring 2016 Observing Program of Brilliant Sky Observatory: Measurements of 313 Pairs. JDSO, 13(1):104-121.

Hensley, H. (2018). The Double Star Orbit Initial Value Problem. Journal of Double Star Observations, 14:353-356.

Hensley, H., Giles, A., Mayhue, L., Badami, U. A., and Tock, K. (2018). CCD Measurements and Linear Solution for WDS 02041-7115. JDSO, 14(1):30-37.

Johnson, C. C. (2012). Implementation of STEM education policy: Challenges, progress, and lessons learned. School Science and Mathematics, 112(1):45-55.

Kastberg, D., Chan, J. Y., and Murray, G. (2016). Performance of US 15-Year-Old Students in Science, Reading, and Mathematics Literacy in an International Context: First Look at PISA 2015. NCES 2017-048. National Center for Education Statistics.

Kith, C., Wilson, J., Agro, S., Toms, S., Andreski, B., Torrance, E., and Tock, K. (2018). CCD Astrometric Measurements of WDS 00420-5547 MLO 1. JDSO, 14(1):138-146.

National Research Council (2010). Preparing teachers: Building evidence for sound policy. National Academies Press.

National Research Council (2011). New worlds, new horizons in astronomy and astrophysics. National Academies Press.

NGSS Lead States (2013). Next generation science standards: For states, by states (Vol 1) Washington.

Pangalos-Scott, S., Holden, D., Fyre, M., Medici, Z., Lee, J., Doughty, M., Chamberlain, R., Freed, R., and Genet, R. (2019). Astrometric Measurements of WDS 13169+ 1701 Binary Star System in Coma Berenices. JDSO, 15(2):255-259. 
Phillips, E., Harrington, M., Rodriguez, M., Jimenez, J., Lee, M., Lopez, P. M., Ramirez, L., Santos, L., Ewing, J.-P., Freed, R., et al. (2019). Astrometry of STF 1510. JDSO, 15(2):210-212.

Reichart, D., Nysewander, M., Moran, J., Bartelme, J., Bayliss, M., Foster, A., Clemens, J., Price, P., Evans, C., Salmonson, J., et al. (2005). PROMPT: panchromatic robotic optical monitoring and polarimetry telescopes. arXiv preprint astroph/0502429.

Tock, K. (2018). Building an Online Astronomy Research Student Team at Stanford Online High School. RTSRE, 1(1):271-279.

Wenger, E. (1999). Communities of practice: Learning, meaning, and identity. Cambridge university press.

Wenger, E., McDermott, R. A., and Snyder, W. (2002). Cultivating communities of practice: A guide to managing knowledge. Harvard Business Press. 